\title{
Produksi Video Promosi Produk Mekari dan Video After Movie Jurnal Partner Awards and Dinner di PT Mid Solusi Nusantara
}

\section{(The Production of Mekari Product Promotion Video and After Movie of Jurnal Partner Awards and Dinner at PT Mid Solusi Nusantara)}

\author{
Muhamad Rafif Fadhillah ${ }^{1}$ Gema Parasti Mindara ${ }^{2}$ Fifi Novianti ${ }^{3}$
}

\footnotetext{
${ }^{1}$ Manajemen Informatika Sekolah Vokasi IPB, Jl. Kumbang No. 14, Bogor, Indonesia

${ }^{2}$ Manajemen Informatika Sekolah Vokasi IPB, Jl. Kumbang No. 14, Bogor, Indonesia

${ }^{3}$ PT Mid Solusi Nusantara, Jl. Jend Sudirman Kav. 10-11, Jakarta Pusat, Indonesia
}

Email : mrafif.fadhillah@gmail.com,gemaparasti@gmail.com fifi.novianti@jurnal.id

\begin{abstract}
PT Mid Solusi Nusantara or commonly known as Mekari, is a company engaged in IT that is making software. Mekari has products such as Journal, Talent, Sleekr, and KlikPajak. Mekari in promoting its products through social media facilities such as Youtube and Instagram. Promotions include graphic design, motion graphics and videography. However, promotion in the form of videography is rarely done because the Creative Marketing division in particular the videography section is still not active on a regular basis for video production. Therefore, the production of videography is aimed at increasing the value of Mekari products and to recognize Mekari products to other businesses.

The Field Work Practices Activity (PKL) is carried out in the Mid Plaza 2 Building, located on Jalan Jend. Sudirman Kav. 10-11, Jakarta Pusat, 10220, Indonesia. This street vendor activity began on February 11, 2019 until May 3, 2019. Data collection was carried out using direct observation techniques, active participation, interviews, and discussions.

The method used in video production involves three stages. These stages include Pre-Production, Production and Post-Production. Stages made in accordance with what was done during the Field Work Practices (PKL) both when working on the script, meeting with clients and video production processes such as editing, rendering to publication.

The results of the video have been made as a promotional media for Mekari companies and the general public who want to find a platform for businesses that are increasingly developing in Indonesia.
\end{abstract}

Key words: editing, production, video, videography.

\section{ABSTRAK}

PT Mid Solusi Nusantara atau biasa dikenal dengan Mekari, merupakan perusahaan yang bergerak dibidang IT yaitu membuat software. Mekari mempunyai produk yaitu Jurnal, Talenta, Sleekr, dan KlikPajak. Mekari dalam melakukan promosi produknya melalui sarana media sosial seperti Youtube dan Instagram. Promosi yang dilakukan berupa desain grafis, motion graphic dan videografi. Namun, promosi berupa videografi jarang dilakukan karena pada 
bagian divisi Marketing Creative khususnya bagian videografi masih belum aktif secara rutin untuk melakukan produksi video. Maka dari itu, produksi videografi dilakukan bertujuan untuk meningkatkan nilai produk - produk Mekari dan untuk mengenali produk - produk Mekari kepada pembisnis lainnya.

Kegiatan Praktik Kerja Lapangan (PKL) dilaksanakan di Gedung Mid Plaza 2, yang berlokasi di Jalan Jend. Sudirman Kav. 10-11, Jakarta Pusat, 10220, Indonesia. Kegiatan PKL ini dimulai pada tanggal 11 Februari 2019 sampai 3 Mei 2019. Pengumpulan data dilakukan dengan menggunakan teknik observasi langsung, partisipasi aktif, wawancara, dan diskusi.

Metode yang digunakan dalam produksi video melibatkan tiga tahapan. Tahapan tersebut antara lain Pra Produksi, Produksi dan Pasca Produksi. Tahapan yang dibuat sesuai dengan apa yang dilakukan saat Praktik Kerja Lapang (PKL) baik saat mengerjakan script, bertemu dengan klien maupun proses produksi video seperti editing, rendering hingga publikasi.

Hasil video yang telah dibuat sebagai media promosi untuk perusahaan Mekari dan masyarakat umum yang ingin mengetahui satu platform untuk bisnis yang semakin berkembang di Indonesia.

Kata kunci : editing, produksi, video, videografi.

\section{PENDAHULUAN}

Di era digital saat ini, perkembangan teknologi multimedia telah menjanjikan berpotensi besar dalam merubah cara seseorang untuk belajar, memperoleh informasi, dan menyesuaikan informasi, hal ini disebabkan oleh adanya tayangan visual serta audio visual. Multimedia adalah kombinasi dari seni, teks, suara, animasi, dan video yang berisi informasi yang disajikan melalui komputer atau alat elektronik lainnya yang dapat dimanipulasi secara digital (Vaughan 2011:18). Teknologi multimedia umumnya digunakan oleh perusahaan yang sedang berkembang dalam mempromosikan produknya. Seperti yang dilakukan oleh PT Mid Solusi Nusantara.

PT Mid Solusi Nusantara atau biasa disebut Mekari merupakan perusahaan yang bergerak dibidang aplikasi laporan keuangan, mengelola karyawan, penggajian karyawan serta perpajakan. Mekari memiliki nama produk dari setiap bidangnya, salah satunya yaitu Jurnal dan Talenta. Jurnal adalah aplikasi akuntansi online yang mengelola laporan keuangan perusahaan secara instan dan real-time. Talenta adalah aplikasi proses administrasi pengelolaan karyawan dan penggajian karyawan.

Kedua produk tersebut, dalam melakukan promosinya menggunakan sarana media sosial seperti Youtube dan Instagram. Media sosial adalah sebuah media online, dengan para penggunanya bisa berpartisipasi, berbagi, menciptakan isi meliputi blog, jejaring sosial, wiki, forum dan dunia virtual. Selain itu, media sosial ini juga dimanfaatkan sebagai strategi marketing oleh Mekari.

Mekari memiliki divisi Marketing Creative yang berperan dalam membuat konten multimedia untuk mempromosikan produk - produk yang dimiliki oleh Mekari. Promosi adalah segala macam bentuk komunikasi persuasi yang dirancang untuk menginformasikan pelanggan tentang produk atau jasa dan untuk 
mempengaruhi mereka agar membeli barang atau jasa tersebut yang mencakup publisitas, penjualan, perorangan dan periklanan (Rangkuti 2009).

Divisi Marketing Creative sudah banyak dalam mempublikasikan konten multimedia diberbagai media sosial resmi produk-produk milik Mekari, seperti desain grafis dan video tutorial. Namun untuk pembuatan konten multimedia berbentuk videografi jarang diproduksi. Maka dari itu, dibuatlah konten multimedia berjudul "Introducing Jurnal" yang berisi informasi tentang memperkenalkan fiturfitur serta keuntungan dari produk Jurnal.

Sebenarnya, divisi marketing creative sudah memiliki satu konten multimedia yang tetap yaitu Customer Story. Pada kenyataannya, konten customer story ini jarang diproduksi oleh Mekari, maka dibuatlah kembali video customer story dengan customer yang baru yaitu PT Altima Group yang memiliki produk yaitu Porto Bistreu dan Nanny's Pavillon. Customer Story merupakan konten multimedia yang berisi informasi testimonial customer selama menggunakan produk Talenta. Selain itu, divisi marketing creative ini juga telah membuat satu konten pada tahun 2019 yaitu "After Movie Jurnal Partner Awards and Dinner 2019" yang berisi informasi apresiasi Jurnal kepada partner. Sehingga, Jurnal dan Talenta telah dipercayai oleh beberapa perusahaan seperti Gojek, Sharetea, Rollover Reaction, dan PT Altima Group.

Berdasarkan latar belakang yang telah diuraikan diatas, melalui pembuatan tugas akhir ini maka judul yang dipilih adalah "Produksi Video Promosi Produk Mekari dan Video After Movie Jurnal Partner Awards and Dinner di PT Mid Solusi Nusantara"

\section{METODE PENELITIAN}

Metode yang digunakan dalam produk multimedia ini berdasarkan tahapan pengerjaan selama praktik kerja lapangan berlangsung. Terdapat satu metode dalam pengerjaan produksi video Introducing Jurnal, video Customer Story hingga video After Movie Jurnal Partner Awards and Dinner 2019. Berikut metode yang digunakan :

Tabel 1 Metode Bidang Kajian

\begin{tabular}{|c|c|c|c|c|c|c|c|c|c|c|}
\hline \multicolumn{5}{|c|}{ Pra Produksi } & \multicolumn{2}{|c|}{ Produksi } & \multicolumn{4}{|c|}{ Pasca Produksi } \\
\hline & DK & PS & PS1 & PP & $P G$ & PD & PE & $\mathrm{RD}$ & $\mathrm{KR}$ & PB \\
\hline $\begin{array}{c}\text { Video Introducing } \\
\text { Jurnal }\end{array}$ & $\sqrt{ }$ & $\sqrt{ }$ & $x$ & $\sqrt{ }$ & $x$ & $\sqrt{ }$ & $\sqrt{ }$ & $\sqrt{ }$ & $\sqrt{ }$ & $\sqrt{ }$ \\
\hline $\begin{array}{c}\text { Video Customer } \\
\text { Story }\end{array}$ & $\sqrt{ }$ & $\sqrt{ }$ & $x$ & $\sqrt{ }$ & $\sqrt{ }$ & $\sqrt{ }$ & $\sqrt{ }$ & $\sqrt{ }$ & $\sqrt{ }$ & $\sqrt{ }$ \\
\hline Video After Movie & $\sqrt{ }$ & $x$ & $\sqrt{ }$ & $\sqrt{ }$ & $x$ & $\sqrt{ }$ & $\sqrt{ }$ & $\sqrt{ }$ & $\sqrt{ }$ & $\sqrt{ }$ \\
\hline
\end{tabular}

Catatan:

$\sqrt{ }$ Dilakukan

$\times$ Tidak dilakukan 


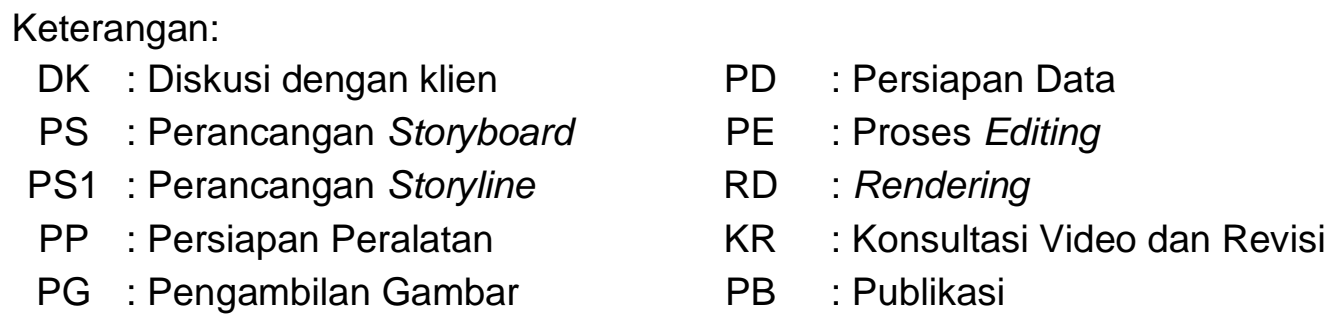

Pada Tabel 1 diatas adalah metode yang digunakan dalam tahap produksi video promosi video produk Mekari dan video after movie. Video promosi produk Mekari terdiri dari 2 video, yaitu introducing Jurnal dan video customer story. Tahap produksi video tersebut meliputi pra produksi, produksi dan pasca produksi. Pada tahapan masing - masing video yang dilakukan terdapat berbeda, seperti yang terlihat pada Tabel 1. Ada beberapa tahapan yang diberi simbol $\mathrm{x}$ disetiap tahapannya, karena pada tahapan itu tidak dilakukan atau tidak dikerjakan pada saat praktik kerja lapang. Berikut penjelasan tahapan - tahapan pada Tabel 1 diatas :

\section{Pra Produksi}

Tahap pra produksi atau perencanaan adalah tahap yang mengacu pada hal-hal yang dilakukan oleh tim produksi sebelum eksekusi pengambilan gambar (shooting) dalam membuat sebuah film (Nurul Muslimin 2018: 30). Kegiatan dimulai dari pembahasan ide gagasan awal hingga pelaksanaan pengambilan gambar (shooting) di lapangan. Tahap pra produksi yang dilakukan dalam pembuatan video adalah :

1 Diskusi denganklien, pada tahap ini diskusi yang dilakukan dengan memberi arahan tentang projek yang akan di produksi. Menurut Kamus Besar Bahasa Indonesia (KBBI) diskusi adalah hal yang dilakukan oleh sekelompok orang yang membahas suatu topik yang menjadi perhatian umum di hadapan khalayak, pendengar (siaran radio), atau penonton (siaran televisi), khalayak diberi kesempatan untuk bertanya atau memberikan pendapat. Menurut Kamus Besar Bahasa Indonesia (KBBI) arahan adalah perintah resmi seorang pemimpin perusahaan kepada bawahannya yang berupa petunjuk untuk melaksanakan sesuatu dan jika tidak dilaksanakan akan mendapat sanksi. Hasil dari diskusi yang dilakukan menjadi sebuah script. Script merupakan hasil kerja tertulis yang menjadi bahan pembuatan film (Effendy 2014: 133).

2 Perancangan Storyboard atau Storyline, pada tahap ini script yang telah dibuat dikembangkan menjadi deskripsi detail yang berisi alur. Menurut Heru Effendy (2014) Storyboard adalah sejumlah sketsa yang menggambarkan aksi di dalam film dan dilengkapi dengan dialog yang sesuai waktunya atau deskripsi adegan. Sedangkan storyline adalah inti dari sebuah script yang diambil dari gagasan utama script tersebut yang dibuat seperti alur cerita. Storyboard atau storyline yang sudah disepakati akan dijadikan acuan dan standar atas tujuan dari produksi yang ingin dicapai. 
3 Persiapan peralatan, tahap ini adalah dilakukan nya pencarian alat disesuaikan dengan kebutuhan pada proses produksi.

\section{Produksi}

Tahap produksi adalah proses yang fokus pada pengambilan gambar/visual beserta audio dari sebuah film. Biasanya disebut shooting day (Nurul Muslimin 2018:104). Pengambilan gambar yang dilakukan pada proses ini ditentukan setelah storyboard atau storyline sudah dibuat. Berikut tahap produksi yang dilakukan adalah :

1 Pengambilan Gambar atau Shooting, merupakan kegiatan yang dilakukan oleh Videographer untuk melakukan pengambilan gambar dalam mengolah rancangan produksi menjadi film.

2 Persiapan Data Video, merupakan persiapan data video yang diambil dari Videographer untuk memudahkan saat proses editing video pada tahap pasca produksi (Hendratman 2017:717).

\section{Pasca Produksi}

Tahap pasca produksi merupakan proses penyelesaian akhir dari produksi (Mabruri 2018:376). Tahap ini juga memproses video sebelum video siap disajikan atau ditayangkan.

1 Video Editing, Menurut Roy Thompson and Christopher J. Bowen (2009) Editing adalah proses mengorganisir, reviewing, memilih, dan menyusun gambar dan suara hasil rekaman produksi. Editing harus menghasilkan tayangan gambar yang padu dan cerita yang penuh makna sesuai apa yang telah direncanakan sebelumnya yaitu untuk menghibur, menginformasikan, memberi inspirasi dan lainnya. Menurut Anton Marburi (2014:53-61), Editing memiliki dua tahapan yaitu Offline Editing dan Online Editing. Offline Editing merupakan merupakan tahap penyuntingan kasar yang intinya adalah menyambung cuplikan - cuplikan gambar terbaik dari setiap adegan dan menyambungkan menjadi satu kesatuan adegan yang berkesinambungan (Mabruri 2018:375). Offline Editing meliputi salah pemotong gambar dalam bentuk kasar, menambahkan background music serta menambahkan voice over. Voice over merupakan istilah suara pengisi tanpa wajah yang menyuarakan tampak di layar, biasanya menggunakan dubber, menggunakan wawancara, dan juga ilustrasi musik sebagai penunjang gambar (Mabruri 2018:314). Sedangkan, Online Editing merupakan lanjutan dari tahap offline editing dimana potongan gambar yang masih kasar disempurnakan dengan cara memberi motion graphic pada gambar, penyempurnaan audio yang masih kasar sesuai dengan kebutuhan, memperbaiki kualitas warna dalam visual biasanya disebut Color Grading (Mabruri 2018:372), efek suara khusus berdasarkan yang dibutuhkan serta memberi tambahan transisi. Motion graphics Transisi adalah proses perpindahan gambar antara scene yang satu dengan scene yang lain (Mabruri 2018:381). 
2 Rendering, merupakan proses kompresi hasil editing menjadi video digital. Sequence atau timeline yang berada di dalam Adobe Premiere Pro akan dikompresi ke dalam ekstensi .mp4. Sequence adalah serangkaian adegan atau shot yang merupakan suatu kesatuan yang utuh (Effendy 2014:135). Adegan atau shot diperoleh dari pengambilan gambar.

3 Konsultasi Video dan Revisi, Menurut Kamus Besar Bahasa Indonesia (KBBI) Revisi adalah peninjauan (pemeriksaan) kembali untuk perbaikan. Pada tahap ini dilakukan perbaikan video yang memperlihatkan karya video sudah sesuai dengan kriteria yang diinginkan oleh klien.

4 Publikasi, merupakan tahap akhir dalam pasca produksi, video akhir yang telah selesai akan dipublikasian ke media sosial yaitu akun Youtube masingmasing produk dari PT Mid Solusi Nusantara.

\section{HASIL DAN PEMBAHASAN}

Pada bab ini membahas tentang implementasi dari metode produksi video yang digunakan dalam pembuatan produk multimedia yang dibuat di PT Mid Solusi Nusantara. Produk multimedia yang dibuat yaitu video promosi dan video after movie. Video promosi terdiri dari "Video Introducing Jurnal" dan "Video Customer Story", untuk video after movie yang dibuat yaitu "Video After Movie Jurnal Partner Awards and Dinner 2019".

\section{Video Introducing Jurnal}

Produk video promosi yang akan dibuat adalah video Introducing Jurnal. Video Introducing Jurnal merupakan video branding ulang produk Jurnal yang sekarang sudah mempunyai company name baru yaitu Mekari. Bertujuan untuk memberikan pengenalan fitur - fitur baru yang ada di produk Jurnal kepada perusahaan yang tertarik bergabung menjadi partner Jurnal. Pada video Introducing Jurnal, ditugaskan khusus menjadi editor video. Namun, editor juga mengikuti tahapan proses pra produksi hingga pasca produksi pada video Introducing Jurnal. Berikut adalah tahapan - tahapan produksi video Introducing Jurnal:

\subsection{Pra Produksi}

Tahap awal pembuatan video Introducing Jurnal dilakukan dengan tahapan pra produksi. Tahap ini adalah tahapan yang penting dalam sebuah proses produksi. Perencanaan yang telah dilakukan melalui diskusi dan dicatat, maka saat nanti diproduksi akan sesuai dengan perencanaan tersebut. Tahap ini terdiri dari beberapa kegiatan perencanaan diantaranya adalah:

\subsubsection{Diskusi dengan klien}

Head of Creative memberikan tugas kepada editor untuk membuat sebuah video Content Advertising berupa Introducing Jurnal. Pada tahap ini diskusi dengan klien yang dilakukan bersama Senior Video Producer sebagai klien nya. Senior Video Producer memberikan arahan dan ide - ide kepada editor tentang 
pembuatan video Intoducing Jurnal yang akan di produksi. Diskusi yang dilakukan meliputi beberapa tahap yaitu konsep video, tujuan video, target audience dan durasi video.

\section{$1 \quad$ Konsep Video}

Senior Video Producer dan Editor mendiskusikan konsep video yang akan ditampilkan. Konsep tersebut yaitu menggambarkan suasanapenggunaan produk Jurnal yang dilakukan oleh customer serta keunggulan produk Jurnal.

\section{Tujuan Video}

Dibuatnya video Introducing Jurnal yaitu sebagai media promosi untuk mengenalkan sebuah software accounting online yang memudahkan karyawan dalam bekerja.

\section{Target Audience}

Ditunjukan kepada perusahaan yang ingin menggunakan produk Jurnal sebagai aplikasi akuntasi online pada perusahaan mereka.

4

Durasi Video

Durasi yang digunakan dalam video Introducing Jurnal yaitu berdurasi berkisaran 1 - 2 menit. Kisaran durasi tersebut ditentukan oleh Senior Video Producer. Menurut Senior Video Producer dari PT Mid Solusi Nusantara video promosi sebaiknya dengan durasi yang singkat dan tersampaikan pesan nya.

Hasil diskusi yang meliputi beberapa tahap diatas menghasilkan sebuah script yang akan dibuat menjadi storyboard pada tahap selanjutnya. Script tersebut dapat dilihat pada Lampiran 1.

\subsubsection{Perancangan Storyboard}

Konsep cerita yang sudah didiskusikan menjadi sebuah script akan dibuat penyajian visual cerita yang menjelaskan tentang alur narasi yaitu Storyboard. Storyboard berisikan pengambilan gambar yang berasal dari Senior Video Producer sebagai director shot. Storyboard berisikan pengambilan gambar shot demi shot, dan bisa pula berupa gambar sketsa dari sebuah scene.

Secara visual inilah yang dijadikan sebagai acuan dalam pengambilan gambar. Jika storyboard sudah disepakati semua tim maka akan dijadikan acuan dan standard tujuan dari produksi yang ingin dicapai. Storyboard yang dibuat untuk acuan pembuatan video Introducing Jurnal seperti yang ditunjukan pada Tabel 2.

Tabel 2 Storyboard Video Introducing Jurnal

\begin{tabular}{|c|c|c|}
\hline No. & Gambar & Penjelasan \\
\hline \multirow{4}{*}{1.} & & Scene 1 \\
\hline & & Opening logo Jurnal. \\
\hline & & Voice Over \\
\hline & & $\begin{array}{l}\text { "Jurnal, software akuntansi online yang } \\
\text { telah dipercaya ribuan bisnis kecil dan } \\
\text { menengah di Indonesia" Teknik }\end{array}$ \\
\hline
\end{tabular}




\section{pengambilan gambar Long Shot \\ Background Music}

A Real Estate

Perkiraan Durasi

7 detik

\subsubsection{Persiapan Peralatan}

Persiapan peralatan dilakukan dengan pendataan terhadap perlengkapan yang akan dipakai. Persiapan tersebut yaitu dilakukanya pemeriksaan secara langsung agar tidak terjadi kesalahan pada saat melakukan proses produksi. Adapun pemeriksaan alat-alat yang akan digunakan yaitu :

\section{Memory Card}

Persiapan memory card dilakukan bertujuan untuk pengambilan data hasil shooting yang akan dilakukan oleh Videographer. Memory card tersebut adalah SanDisk 32 GB (3 buah).

\section{Komputer}

Komputer digunakan untuk proses produksi dan pasca produksi dalam kebetuhan pemilihan stock footages dan mengedit video yang telah di shooting oleh Videographer. Berikut spesifikasi komputer yang digunakan seperti yang dtunjukan pada Tabel 3.

Tabel 3 Spesifikasi Komputer

\begin{tabular}{cc}
\hline Perangkat Keras & Spesifikasi \\
\hline Operating System & macOS Sierra \\
Processor & $2,7 \mathrm{GHz}$ Intel Core i5 \\
System Manufacture & iMac \\
System Model & iMac 2012 \\
Memory & 16 GB $1600 \mathrm{MHz}$ DDR3 \\
Harddisk & I TB (SATA Disk) \\
Alat Input & Keyboard dan Mouse \\
Alat Output & Earphone
\end{tabular}

Pada tabel spesifikasi komputer di atas sudah memenuhi kriteria minimun komputer yang digunakan untuk tahapan produksi dan pasca produksi khusus nya pada tahapan editing dan rendering.

\subsection{Produksi}

\subsubsection{Persiapan Data}

Pada proses ini dilakukan persiapan data, data yang diambil berupa video mentahan dari hasil pengambilan gambar yang dilakukan oleh Videographer. 
Videographer memberikan memory card kepada editor saat setelah melakukan proses pengambilan gambar. Kemudian editor melakukan pemilihan data video dan dipisahkan setiap adegannya dilakukan berdasarkan storyboard yang sudah dibuat pada proses pra produksi. Persiapan data video dapat dilihat pada Gambar 1.
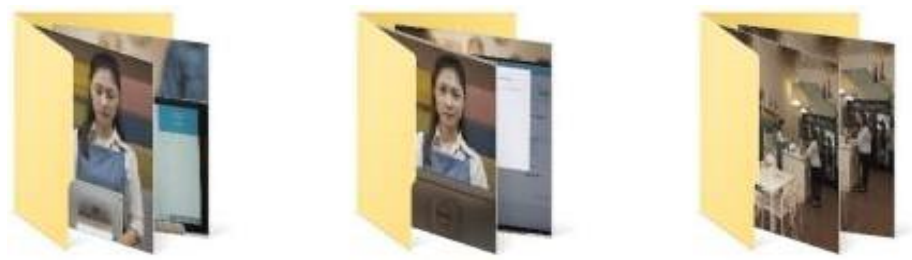

Gambar 1 Persiapan Data Video-Video Introducing Jurnal

\subsection{Pasca Produksi}

\subsubsection{Proses Editing}

Proses Editing merupakan suatu proses semua bahan video yang sudah terkumpul diolah menjadi video yang utuh. Proses editing ini memilih atau menyunting gambar dari hasil shooting yang dilakukan oleh Videographer dan sudah dipilih scene yang sesuai dengan storyboard yang dilakukan oleh Editor. Proses editing yang dilakukan dengan cara memotong gambar ke gambar (cut to cut) atau dengan menggabungkan gambar-gambar dengan menyisipkan sebuah transisi. Perangkat lunak yang digunakan dalam proses editing yaitu :

1 Adobe Premiere Pro CC 2018

Perangkat lunak yang digunakan untuk mengedit video.

\section{Adobe After Effect CC 2018}

Perangkat lunak yang digunakan untuk membuat motion graphic.

Perangkat lunak yang sudah disebutkan di atas, umum nya digunakan untuk melakukan editing, karena software editing ini sudah modern dengan sistemkerja yang lebih sederhana dan mudah dipahami dalam pengoperasian nya.

Setelah semuanya sudah dibuat, selanjutnya ke proses editing ini memiliki beberapa tahapan yaitu:

1 Offline editing

Merupakan tahapan pemotong bahan video yang akan digunakan dalam bentuk kasar, menambahkan background music dan menambahkan voice over.

a. Memasukkan Background Music

Background Music adalah lagu yang akan diputar atau dimainkan sebagai latar dan pemanis dalam sebuah karya video. Background Music yang dipakai sudah ditentukan pada pembuatan storyboard yang telah dibuat. Pada video Introducing Jurnal menggunakan background music yaitu $A$ Real Estate yang diunggah dari Youtube, lagu tersebut berlisensi free no copyright. 


\section{b. Pemotongan Video}

Video mentah yang telah dipilih kemudian dilakukan penyeleksi yang biasa disebut cut to cut. Penyeleksian video yang dilakukan menyesuaikan dengan scene yang ada didalam storyboard yang telah dibuat. Tahapan penyeleksian video dapat dilihat pada Gambar 2.

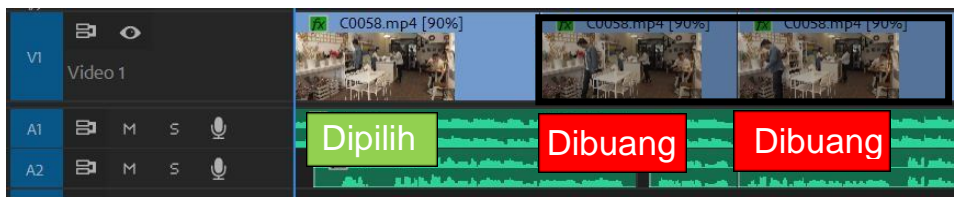

Gambar 2 Tahapan Penyeleksian Video

c. Menambahkan voice over

Voice over yang sudah direkam oleh Videographer, kemudian di import ke dalam software Adobe Premiere Pro, selanjutnya disesuaikan dengan scene yang ada didalam storyboard.

\section{Online editing}

Merupakan tahapan lanjutan dari tahap offline editing dimana potongan gambar yang masih kasar akan disempurnakan dengan cara memberi motion graphic pada gambar sesuai kebutuhn dan keseimbangan suara pada background music, efek suara dan voice over. Tahap ini meliputi penambahan motion graphic, color grading serta efek suara.

\section{a. Penambahan motion graphic}

Pada tahap melakukan penambahan motion graphic dibuat menggunakan software Adobe After Effects CC 2018. Teknik yang digunakan untuk membuat motion graphic yaitu teknik Masking. Teknik masking adalah teknik menyembunyikan teks dan objek dari suatu objek. Teknik masking dapat dilihat pada Gambar 3.

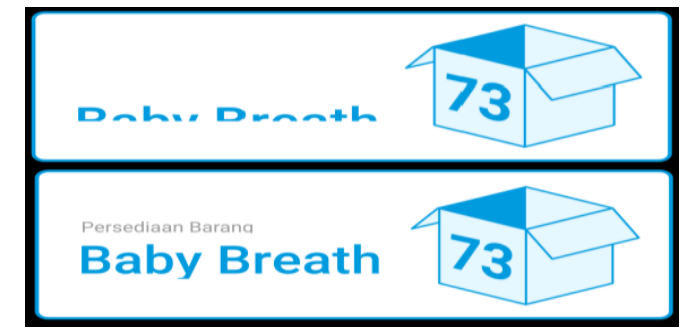

Gambar 3 Contoh Penerapan Teknik Masking

\section{b. Color Grading}

Pada video Introducing Jurnal proses color grading dilakukan menggunakan plug-in lumetri color yang sudah disediakan pada software Adobe Premiere Pro CC 2018. Hasil color grading dapat dilihat pada Gambar 4.

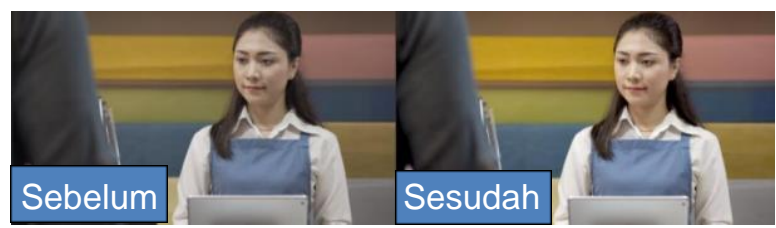

Gambar 4 Perubahan Color Grading - Video Introducing Jurnal 


\section{c. Efek suara}

Pada tahap efek suara sangat diperlukan untuk mengatur besar kecilnya background music, voice over, dan sound effects. Pada video Introducing Jurnal menggunakan salah satu plug-in audio transitions dari software Adobe Premiere Pro CC 2018 yaitu constant power. Efek suara tersebut dapat dilihat pada Gambar 5.

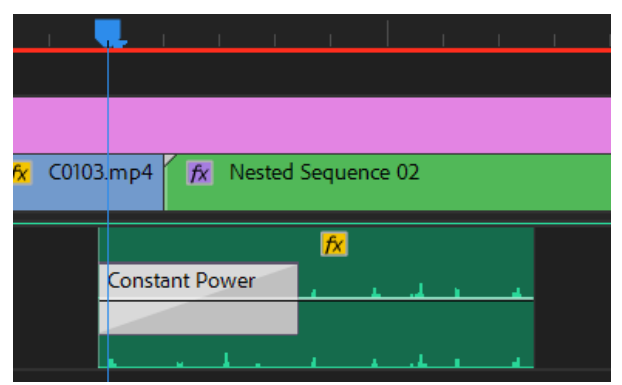

Gambar 5 Efek Suara - Constant Power

\subsubsection{Rendering}

Setelah semua video melalui tahap proses editing, selanjutnya video memasuki tahap akhir sebelum video menjadi final. Rendering yang dilakukan pertama yaitu rendering pada motion graphic, karena proses rendering motion graphic melalui software Adobe After Effects CC 2018 dan editing final video dilakukan pada software Adobe Premiere Pro CC 2018.

\subsubsection{Konsultasi Video dan Revisi}

Setelah proses editing dan rendering telah selesai maka video sudah bisa diperlihatkan dan dikonsultasikan kepada Senior Video Producer. Jika video masih terdapat kesalahan atau belum sesuai dengan tujuan yang ingin dicapai maka akan dilakukan revisi. Revisi dilakukan agar video bisa layak untuk di publikasi. Revisi tersebut dapat dilihat pada Gambar 6.
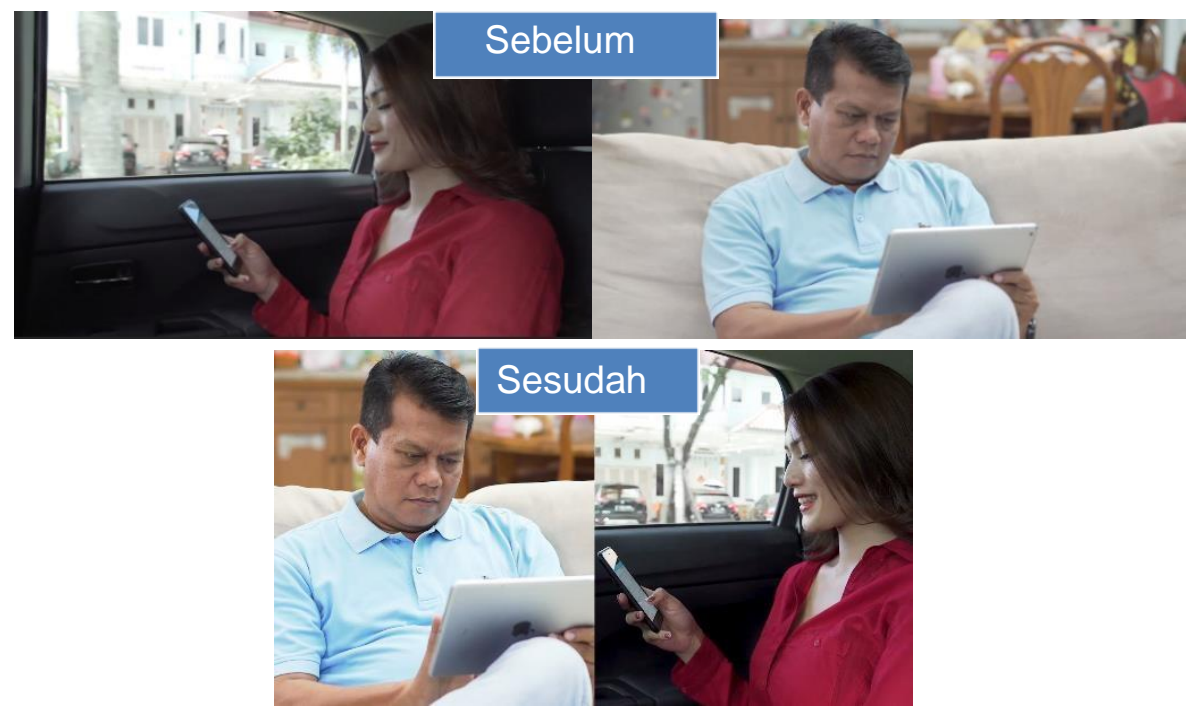

Gambar 6 Revisi Perubahan Scene - Video Introducing Jurnal 


\subsubsection{Publikasi}

Setelah proses revisi telah selesai dan sudah mencapai hasil final dari video yang telah dibuat maka video akan dipublikasi oleh Senior Video Producer melalui akun Youtube Jurnal.

\section{Video Customer Story}

Produk video promosi yang akan dibuat selanjutnya adalah video Customer Story. Content video customer story berisikan tentang testimonial customer selama menggunakan produk dari PT Mid Solusi Nusantara yang bertujuan untuk memberikan kepuasan kepada customer dan bisa memikat customer yang belum bekerjasama menjadi partner.

Tahapan video customer story masih sama seperti tahapan pada video sebelumnya dari tahapan pra produksi yang memulai diskusi dengan klien sampai persiapan peralatan dan tahapan pasca produksi juga masih sama dengan video sebelumnya mulai dari proses editing hingga publikasi, namun ada perbedaan dibagian produksi. Berikut tahapan produksi yang dilakukan:

\subsection{Produksi}

Tahap produksi adalah tahap eksekusi dari persiapan yang sudah dilakukan pada tahap pra produksi. Ada tahapan yang berbeda dengan proses produksi pada Introducing Jurnal. Berikut tahapan yang dilakukan saat produksi :

\subsubsection{Shooting}

Pada tahap ini dilakukan teknik pengambilan gambar yang sesuai dengan storyboard sebagai acuan nya. Pada proses pengambilan gambar digunakan beberapa teknik pengambilan berikut teknik pengambilan gambar, high camera angle dapat dilihat pada Gambar 8.

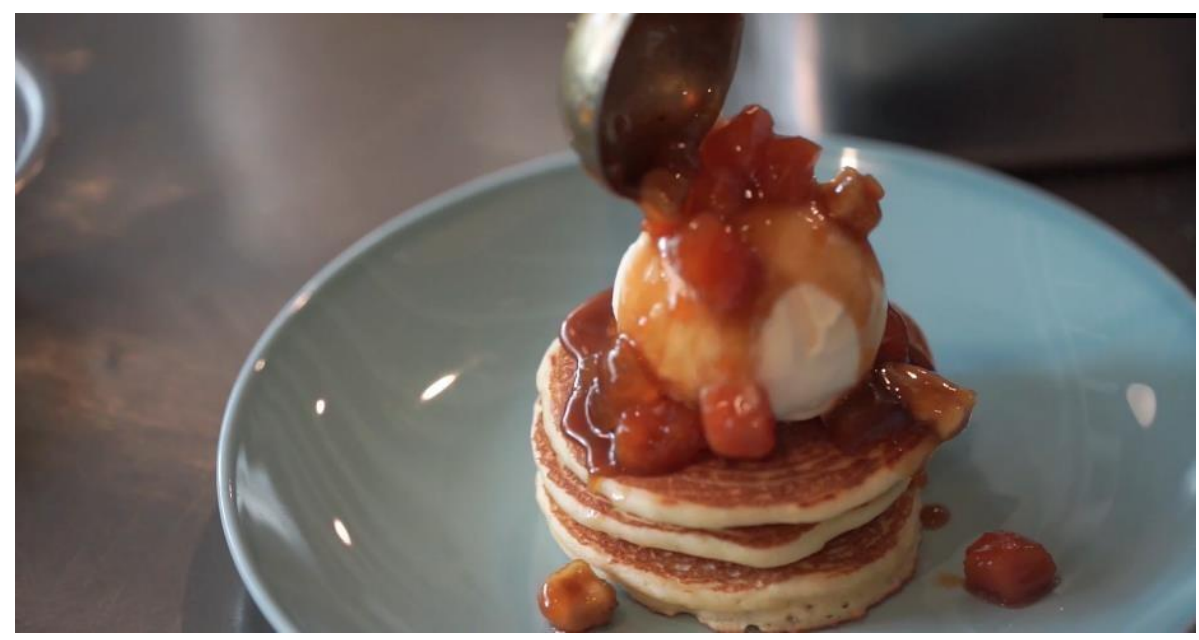

Gambar 7 Camera Angle - High Camera Angle

\subsubsection{Persiapan Data}

Setelah melakukan proses pengambilan gambar, selanjutnya proses persiapan data, persiapan ini sama dengan pada video Introducing Jurnal. Videographer melakukan transfer data hasil shooting dan melakukan pemilihan video sesuai dengan storyboard. 


\section{Video After Movie}

Pada produk multimedia yang akan dibuat selanjutnya adalah video After Movie Jurnal Partner Awards and Dinner 2019. Video after movie merupakan content video setiap tahun dari produk Jurnal. Pada video after movie, ditugaskan menjadi editor. Tahapan yang dilakukan pada video after movie masih sama tahapannya dengan video introducing Jurnal yang sudah dijelaskan yang ditugaskan sebagai editor video, namun ada perbedaan dibagian pra produksi pada tahap perancangan, perancangan yang dilakukan pada video after movie adalah perancangan storyline, berikut perancangan storyline yang dilakukan:

\subsection{Pra Produksi}

\subsubsection{Perancangan Storyline}

Pada tahap ini memiliki perbedaan dari video sebelumnya, karena video ini after movie pada saat proses shooting dilakukan secara real time. Jadi perancangan yang dilakukan yaitu perancangan storyline. Konsep cerita yang sudah didiskusikan dibuat menjadi storyline. Storyline berisikan alur cerita yang akan ada didalam video.

Alur cerita inilah yang dijadikan sebagai acuan dalam pengambilan gambar. Jika storyline sudah disepakati semua tim maka akan dijadikan acuan dan standart tujuan dari produksi yang ingin dicapai. Storyline yang dibuat untuk acuan pembuatan video After Movie seperti yang ditunjukan pada Tabel 4.

Tabel 4 Storyline Video After Movie

\begin{tabular}{cl}
\hline Scene & \multicolumn{1}{c}{ Penjelasan Scene } \\
\hline & $\begin{array}{l}\text { (Opening) Adegan partner sedang masuk dan menunggu acara } \\
\text { mulai, video secara singkat. } \\
\text { Background Music }\end{array}$ \\
& ES_Safe Journey 1 - Magnus Ringblom \\
\hline
\end{tabular}

\section{Pengujian}

\subsection{Pengujian Alpha}

Pada tahap pengujian alpha merupakan pengujian yang dilakukan dengan mempresentasikan hasil video kepada pembimbing lapang. Pada saat mempresentasikan hasilnya dapat diterima dan akan dipublikasi oleh pembimbing lapang.

\subsection{Pengujian Beta}

Tahap pengujian beta, merupakan pengujian yang memberikan dan memperlihatkan video kepada orang lain atau masyarakat yang tidak terlibat dalam pembuatan video. Pengujian beta dilakukan dengan cara membagikan kuisioner pada platform google form kepada rekan kuliah dan umum. Kesimpulan dari pengujian beta dapat dilihat pada Tabel 5. 
Tabel 5 Kesimpulan Pengujian Beta Video Introducing Jurnal

\begin{tabular}{llllll}
\hline \multirow{2}{*}{ No } & \multirow{2}{*}{ Pertanyaan } & \multicolumn{5}{c}{ Jumlah Pemilih } \\
\cline { 3 - 6 } A. Visual & $\mathbf{1}$ & $\mathbf{2}$ & $\mathbf{3}$ & $\mathbf{4}$ & $\mathbf{5}$ \\
\hline 1 & Apakah video sudah terlihat jelas? & 1 & 5 & 14 \\
\hline 2 & Apakah transisi video sudah baik? & 0 & 7 & 13 \\
\hline 3 & $\begin{array}{l}\text { Apakah warna dan pencahayaan } \\
\text { pada video sudah baik? }\end{array}$ & 1 & 7 & 12 \\
\hline $4 \quad \begin{array}{l}\text { Apakah ilustrasi motion graphic } \\
\text { yang ditampilkan sudah sesuai } \\
\text { dengan konten? }\end{array}$ & 0 & 8 & 12 \\
\hline
\end{tabular}

B. Isi

\begin{tabular}{llllc}
\hline 1 & $\begin{array}{l}\text { Apakah informasi yang } \\
\text { disampaikan sudah jelas? }\end{array}$ & 1 & 11 & 8 \\
\hline 2 & $\begin{array}{l}\text { Apakah anda tertarik dengan } \\
\text { konsep video Introducing Jurnal? }\end{array}$ & 2 & 7 & 11 \\
\hline 3 & Apakah durasi video sudah cukup? & 3 & 6 & 11 \\
\hline C. Audio & &
\end{tabular}

\section{Audio}

\begin{tabular}{llccc}
\hline 1 & $\begin{array}{l}\text { Apakah suara narasi lebih besar } \\
\text { dari suara background music? }\end{array}$ & 0 & 11 & 9 \\
\hline 2 & $\begin{array}{l}\text { Apakah narasi sudah terdengar } \\
\text { jelas? }\end{array}$ & 0 & 9 & 11 \\
\hline Jumlah & 0 & 8 & 71 & 101 \\
\hline Persentase & & $4,4 \%$ & $39,4 \%$ & $56,1 \%$ \\
\hline
\end{tabular}

Catatan:
1 Sangat tidak setuju
4 Setuju
2 Tidak setuju
5 Sangat setuju
3 Cukup

\section{SIMPULAN}

Pembuatan video Introducing Jurnal sebagai media promosi dalam memperkenalkan produk Jurnal telah berhasil diselesaikan sampai proses tahap akhir yang terdapat pada metode bidang kajian, yaitu tahap publikasi.

Pembuatan video Customer Story untuk PT Altima Group dalam menampilkan informasi testimonial customer selama menggunakan produk Talenta telah berhasil diselesaikan sampai proses tahap publikasi.

Pembuatan video After Movie Jurnal Partner Awards and Dinner 2019 untuk after movie event telah berhasil diselesaikan sampai proses tahap akhir, yaitu tahap publikasi.

\section{DAFTAR PUSTAKA}

Aziz Abdul. 2017. Color Grading, Teknik Mengubah Suasana Dalam Film. [internet]. [diakses 2019 Mei 18]. Tersedia pada : 
https://medium.com/@azizcrable0n/color-grading-teknik-mengubahsuasana-dalam-film-b4ccc4f27827

CSinema. 2017. Tahapan Produksi Film: Pasca Produksi. [internet]. [diakses 2019 Mei 18]. Tersedia pada : http://csinema.com/tahapanproduksi-film-pasca-produksi/

Effendy H. 2014. Mari Membuat Film. Jakarta (ID) : KPG (Kepustakaan Populer Gramedia.

Hendratman H. 2017. The Magic of Adobe Premiere Pro. Bandung (ID): Informatika Bandung.

HR Primanti. 2012. Produksi Film dan Studio Film. [internet]. [diunduh 2019 April 13]. Tersedia pada : http://e-journal.uajy.ac.id/157/3/2TA12920.pdf

Mabruri A. 2018. Produksi Program TV Non-Drama Manajemen Produksi dan Penulisan Naskah. Jakarta (ID) : PT. Gramedia Widiasarana Indonesia.

Muslimin N. 2018. Bikin Film, Yuk! Yogyakarta (ID): Araska

N Sora. 2017. Pahamilah Pengertian Storyboard Dan Fungsinya. [internet]. [diakses 2019 Mei 18]. Tersedia pada

http://www.pengertianku.net/2017/10/pengertian-storyboard-danfungsinya.html

Nugroho S. 2014. Teknik Dasar Videografi. Yogyakarta. (ID): CV ANDI OFFSET.

Rangkuti F. 2009. Starategi Promosi yang Kreatif dan Analisis Kasus Integrated Marketing Communication. Jakarta (ID): PT.Gramedia Pustaka Utama.

Vaughan T. 2011. Multimedia : Making It Work. [jurnal]. Tersedia pada : library.binus.ac.id/eColls/eThesisdoc/Bab2/2013200400IF\%20Bab2001.p df

Widharma Wayan. 2015. Pengertian Shot, Scene dan Sequence. [internet]. [diakses 2019 Mei 19]. Tersedia pada: http://csinema.com/shot-scene-dansequence/ 